\title{
Using titanium complexes to defeat cancer: the view from the shoulders of titans
}

\author{
Melchior Cini, ${ }^{a}$ Tracey D. Bradshaw ${ }^{\mathrm{b}}$ and Simon Woodward ${ }^{\mathrm{c}}$ \\ a. Institute of Applied Sciences, MCAST Main Campus, Corradino Hill, Paola, PLA 9032. \\ Email: melchior.cini@mcast.edu.mt
}

b. School of Pharmacy, Centre for Biomolecular Science, University of Nottingham, University Park Nottingham, NG7 2RD, UK. Email: tracey.brashaw@nottingham.ac.uk

c. GSK Carbon Neutral Laboratories for Sustainable Chemistry, University of Nottingham, Jubilee Campus, Nottingham NG7 2TU, UK. Email: simon.woodward@nottingham.ac.uk

When the first titanium complex with anticancer activity was identified in the 1970s, it was attractive, based on the presence of the dichloride unit in $\mathrm{TiCl}_{2} \mathrm{Cp}_{2}\left(\mathrm{Cp}=\eta-\mathrm{C}_{5} \mathrm{H}_{5}\right)_{2}$, to assume its mode of biological action was closely aligned with cisplatin [cis- $\left.\mathrm{PtCl}_{2}\left(\mathrm{NH}_{3}\right)_{2}\right]$. Over the intervening 40 years however a far more complicated picture has arisen indicating multiple cellular mechanisms of cellular action can be triggered by titanium anti-cancer agents. This tutorial review aims to unpick the historical data and provide new researchers, without an explicit cancer biology background, a contemporary interpretation of both older and newer literature and to review the best techniques for attaining the identities of the biologically active titanium species and how these interact with the cancer cellular machinery.

\section{Key learning points}

(1) Understanding the problems in defining 'modes of action' in order to effectively design small molecular titanium-based therapeutic, agents when moving beyond simple 'structure vs. activity' correlations.

(2) The dangers of over generalisation in historical 'mode of action' proposals in the absence of rigorous control experiments leading to proposals not fully in line with all (especially later) observations.

(3) Titanium induced cellular morphology changes and contemporary thoughts on mode(s) of action presented in a way chemical scientists can 'get to grips with them' - understanding the hall marks of cellular death modes induced by titanium anti-cancer agents.

(4) Modern tools for probing Ti-drug mechanisms of action, including: chiral probe complexes, added external proteins (transferrin, serum albumin); titanium solution speciation, and an overview of contemporary chemical-biology techniques of relevance to discovery of 'modes/mechanisms of action'.

\section{Introduction}

Anti-cancer $\mathrm{Ti}^{\mathrm{IV}} \mathrm{L}_{\mathrm{n}}$ complexes are a current 'hot' area in bioinorganic chemistry. ${ }^{1,2}$ They are attractive due to potential lower toxicity towards normal tissues (than traditional anti-cancer agents), and also due to an ability to tune cellular action through appropriate ligand choice. The high activities and multiple mechanisms of action shown by 'new generation' titanium-based species offer exciting potential for future clinical trial candidates; both in their own right and in combination with other therapeutic agents. This tutorial review is a 'primer' aimed at newcomers from the chemical sciences to this area who do not necessarily have any cancer biology background. A key requirement for any new drug to reach the clinic is that an active agents' precise molecular and biological target(s) must first be well defined (the so called 'mechanism of action'). Attaining this position for titanium-based pro-drugs is at the core of the discussion herein as it is the current bottleneck in developing 'in clinic' Ti-based therapies. The key issues are: (i) titanium anti-cancer agents can present opaque or conflicting biological data regarding their mechanisms of action and (ii) the precise structures of the active aqueous titanium species involved (and interaction with their exact biological targets) are still poorly defined, even though recent findings include many active compounds stable in water. Titanium(IV) species are potent Lewis acids which can interfere with a wide range of biological (Lewis basic) functions in any of the $\sim 200$ (cancer) cell types in the human body. Thus, perversely to the uninitiated, a single cytotoxic (cell 'killing') titanium complex can engender very different growth behaviour profiles against a range of cancer cell lines (Figure 1). The time-consuming nature of biological studies frequently limits the number of cell lines studied in an individual paper to a handful (at best). This can all too easily lead to over interpretation, and most 
particularly overgeneralisation of results (to other cell lines), posing risks for both the review writer (and new researchers) seeking to make general recommendations for improved titanium therapeutics. Modern cell line databases such as the NCI-60 (see also latert) can help in overcoming such issues, but historically this has been a significant problem.

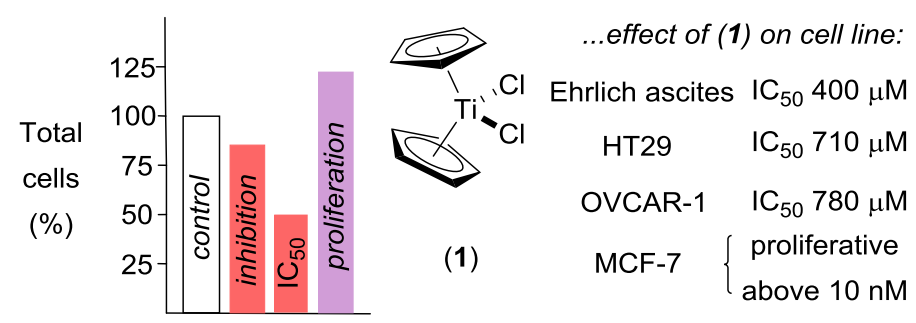

Figure 1. Titanocene dichloride (1) can engender cell line dependent inhibitory and proliferative effects. The concentration inducing a $50 \%$ reduction in cell population at a selected time, IC $_{50}$ (sometimes related $\mathrm{GI}_{50}$ is used $\neq$ ) is typically measured by cell staining, e.g. with the tetrazolium reagent MTT after exposure to $\mathbf{1}$ for a pre-selected time.

For this reason we start this tutorial with an overview of 'mode of action' data attained for titanocene dichloride, $\mathrm{TiCl}_{2} \mathrm{Cp}_{2}\left(\mathrm{Cp} \text {; }=\eta-\mathrm{C}_{5} \mathrm{H}_{5}\right)_{2}$ (1) during the early 'discovery' period 1979-2005, together with a summary of critical chemical biology of relevance to mode of action discovery. This is followed by an outline of more recent experiments (ca. 2005 onwards) indicating that alternative molecular targets might be perturbed, at least by complexes distinct from $\mathrm{Cp}_{2} \mathrm{TiCl}_{2}$, and that additional biological modes of action conclusions can be drawn (Section 3). After a discussion of contemporary mechanistic tools available for the identification of the active titanium therapeutic species and validation of biological modes of action (Section 4) we suggest some potential future paths and strategies for putative therapeutics (Section 5).

\section{Early titanium anti-cancer 'mode(s) of action' suggestions}

In the wake of Rosenburg's seminal discovery (1965-69) of cancer inhibition by cis-PtCl $\left(\mathrm{NH}_{3}\right)_{2}(\mathrm{cisplatin})$ Kopf and Kopf-Maier reported the intuition-driven discovery of apparently related cytostatic (inhibition of cell growth) activity for the metallocene titanocene dichloride (1) in $1979 .^{3}$ Finally, $\mathbf{1}$ reached Phase II clinical trial in the 1990s but did not progress due to lack of in patient efficacy. Initial mode of action studies on $\mathbf{1}$ focused extensively on Ehrlich ascites tumours in mouse models (which presented highly encouraging 'cure' outcomes). DNA-binding, akin to cisplatin, was initially suggested by Kopf-Maier on the basis of: (i) suppression of synthesised DNA/RNA in tritium-labelled thymidine/uridine take up studies over $48 \mathrm{~h}$, and (ii) the observation of apparent 'high levels' of titanium (in nucleic acid rich regions of cells exposed to $\mathbf{1}$ ) by $\mathrm{X}$ ray energy loss spectroscopy (EELS). Unfortunately, the low intensity of the EELS signals observed forced Kopf-Maier to use very high (up to $10 \mathrm{mM}$ ) concentrations of $\mathbf{1}\left(20-25 \times\right.$ the $\mathrm{IC}_{50}$ in this cell line) to detect any signal at all. Subsequent fluorescence studies of V79 hamster lung cells treated with $\mathrm{Cp}_{2} \mathrm{TiCl}_{2}(100 \mu \mathrm{M})$ showed no significant difference in Ti-uptake compared to those not exposed (or indeed to those treated with other non-Ti metallocenes). ${ }^{4}$ However, on the basis of the above experiments Ti uptake and intracellular delivery to a DNA target was typically assumed and proved a popular target for subsequent investigations and interpretations.

Neutral $\mathbf{1}$ is very insoluble $(<5 \mu \mathrm{M})$ in water or cellular growth media and forms colloidal suspensions (even when genuine DMSO solutions of $\mathbf{1}$ are then subjected to subsequent aqueous dilution). By conductivity, after a 50 min induction period associated with its dissolution, Toney ${ }^{5}$ could estimate an effective net first order rate for cleavage of both chlorides in 1 of $0.84 \mathrm{~h}^{-1}\left(\mathrm{t}_{1 / 2} \sim 50 \mathrm{~min}\right)$ to give $\left.\left[\mathrm{Cp}_{2} \mathrm{Ti}_{(\mathrm{OH}}\right)_{2}\right]^{2+}(3.5 \mathrm{mM}$ in aqueous $0.32 \mathrm{M} \mathrm{KNO}_{3}$ at $37{ }^{\circ} \mathrm{C}$ ). By titration two $\mathrm{pK}_{\mathrm{a}}$ ionisation constants for the water ligands bound to $\mathrm{Cp}_{2} \mathrm{Ti}^{2+}$ of 3.5 and 4.35 were attained. This means that at $\mathrm{pH}$ values $\sim 3.5$ the major species is $\left[\mathrm{Cp}_{2} \mathrm{Ti}(\mathrm{OH})\left(\mathrm{OH}_{2}\right)\right]^{+}$while $\left[\mathrm{Cp}_{2} \mathrm{Ti}(\mathrm{OH})_{2}\right]$ should be present above $\mathrm{pH} 4.4$ (blood serum $\mathrm{pH}$ is typically 7.37.4). Although $\left[\mathrm{Cp}_{2} \mathrm{Ti}(\mathrm{OH})\left(\mathrm{OH}_{2}\right)\right]^{+}$has been potentially identified in the early stages of hydrolysis $\left(\delta_{H} \mathrm{Cp}\right.$ $6.62, \mathrm{pH}_{\mathrm{D}} 2.2$ in $\left.\mathrm{D}_{2} \mathrm{O}\right){ }^{6}{ }^{6}$ the dihydroxy complex has not: it readily loses water generating ' $\mathrm{Cp} \mathrm{p}_{2} \mathrm{Ti}(\mathrm{O})^{\prime}$ species that are frequently insoluble and/or not easily charaterised by NMR. Ionisation of $\mathbf{1}$ and subsequent deprotonations of $\left[\mathrm{Cp}_{2} \mathrm{Ti}\left(\mathrm{OH}_{2}\right)_{2}\right]^{2+}$ are much faster $(<15 \mathrm{~min})$ in the presence of added bases. It has been suggested that $\left[\mathrm{Cp}_{2} \mathrm{Ti}(\mathrm{OH})\left(\mathrm{OH}_{2}\right)\right]^{+}$can act as an oestrogen mimic - the cause of the MCF-7 proliferation seen in Figure $1 .^{7}$ Free $\mathrm{CpH}$ is also detected upon aqueous dissolution of $\mathbf{1}$ but this Ti-Cp hydrolysis is actually rather slow $\left(\mathrm{t}_{1 / 2} \sim 102 \mathrm{~h}\right.$ at $37{ }^{\circ} \mathrm{C}$ in $0.32 \mathrm{M} \mathrm{KNO}_{3}$ at $\mathrm{pH} 7.5$, based on appearance of $\mathrm{CpH}$ ). Poorly characterised insoluble mixtures also result from these partial or complete Cp cleavages. What can be said is that the anti-cancer efficacy of the isolated polynuclear hydrolysis products $\left[\left(\mathrm{Cp}_{2} \mathrm{TiCl}\right)_{2}(\mu-\mathrm{O})\right]$ and $\left[(\mathrm{CpTiCl}(\mu-\mathrm{O})]_{4}\right.$ is less than that of $\mathbf{1}$ against Erhlich ascites (cure rates of 54 and $38 \%$ in tumour-bearing mice vs. $100 \%$ for their equivalent treatment with $\mathbf{1}^{3}$ ). This might be taken to 
indicate that the causative anti-cancer agent contains only one titanium centre (but see also later in Section 3). Complexes containing substituted cyclopentandienes such as titanocene $Y \mathbf{3}$ (see Figure 5 for structure) hydrolyse much more slowly than 1 (ca. $72 \mathrm{~h}$ under 'forcing' model conditions: $60{ }^{\circ} \mathrm{C}, 10 \mathrm{mM}$ in $1: 1 \mathrm{D}_{2} \mathrm{O} / \mathrm{DMSO}$ ) but no intermediate was suggested. ${ }^{8}$

Based on the aqueous fragility of $\mathbf{1}$, Sadler suggested that the iron transport protein transferrin (Tf) might provide a 'Trojan horse' for the delivery of 'labile' $\mathrm{Ti}^{4+}$ species into 'iron hungry' cancer cells (Figure 2 )..$^{9} \mathrm{He}$ elegantly showed, that under physiological model conditions $(100 \mathrm{mM} \mathrm{NaCl}, 25 \mathrm{mM}$ hydrogencarbonate and $4 \mathrm{mM}$ phosphate, $\mathrm{pH} 7.4$ ) that $\mathbf{1}$ is readily sequestered by apo (iron-free) transferrin as a $\mathrm{Ti}^{4+} \mathrm{species}$ resulting from rapid (mins) loss of both chloride and cyclopentadienyl ligands from $\mathbf{1}$ - implicating biologically accelerated Cp-Ti hydrolysis (cf. Toney's $t_{1 / 2} \sim 102 \mathrm{~h}$ for Cp-Ti cleavage measured above). NMR studies of Tf metal-induced conformational change strongly support titanium binding to transferrin; $\mathrm{Ti}^{4+}$ from $\mathbf{1}$ is first loaded to the $\mathrm{C}$-lobe of transferrin followed by the $\mathrm{N}$-lobe, resulting in a stable $\mathrm{Ti}_{2}-\mathrm{Tf}_{\mathrm{C}}$ complex. It was proposed this $\mathrm{Ti}_{2}$-Tf complex is then intracellularly transported in membrane-bound compartments (endosomes) leading to release of $\mathrm{Ti}^{4+}$ ions on contact with cellular ATP and subsequent binding to DNA/RNA nucleic acid regions. ${ }^{10}$ While Sadler could show viable $\mathrm{Ti}_{2}-\mathrm{Tf}$ binding to Tf receptors on the surface of the cell (as $\mathrm{Ti}_{2}-\mathrm{Tf}$ blocked the uptake of radioactive ${ }^{59} \mathrm{Fe}-\mathrm{Tf}$ into BeWo cells), mechanisms for the delivery of titanium (within the cell) to DNA remained more speculative. As an alternative to transferrin involvement for titanium delivery into cells the involvement of the ubiquitous blood protein serum albumin (SA) has been suggested as a delivery mechanism for titanocenes. ${ }^{7,8}$ Serum albumin receptors are overly represented on cancer cells and simple molecular modelling indicated a potential titanocene binding site (albeit with the chlorides not dissociated).

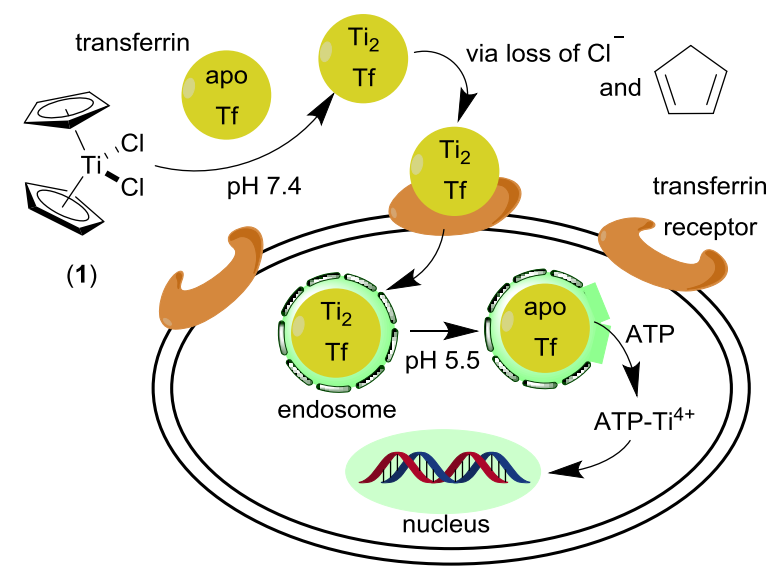

Figure 2. Uptake of $\mathbf{1}$ by transferrin and the hypothesis that this provides a toxic intracellular $\mathrm{Ti}^{4+}$ species (of unknown structure) that interacts with DNA (and/or RNA). ${ }^{9}$

Cisplatin (and its derivatives) are archetypal DNA interfering drugs, often used as reference compounds in anticancer research. The limitations of such platinum-based drugs include: efficacy against only a narrow range of tumours, acquired or intrinsic resistance, nephro- and gastrointestinal toxicity, nausea and bone marrow suppression. Alternatives are highly desired. There are clear indications that the mechanism of action of $\mathbf{1}$ is different from DNA coordinating cisplatin, as evidenced by differences in their nucleic acid metabolism and in the relative efficacy of $\mathbf{1}$ vs. cisplatin against the multiple different cell lines of the USA National Cancer Institute (NCI-60). + Additionally, $\mathbf{1}$ significantly overcomes acquired cisplatin resistance in some cell lines, ${ }^{11}$ e.g. 1 is still active in two human ovarian carcinoma cell lines (A2780CP and $\mathrm{CH} 1$-cisR) that are highly resistant to cisplatin. As cisplatin cytotoxicity is attained through DNA binding, cross-linking and ultimately strand breaks disrupting DNA replication and transcription, the resistance in the ovarian cell lines is directly related to an increased ability in the cancer cell to repair Ptinduced DNA damage. As $\mathbf{1}$ is able to induce growth inhibitory activity in these same cell lines, the mode of action of $\mathbf{1}$ is less likely be related to formation of DNA adducts. Model Lewis acid/base metal-DNA solution binding experiments, using tritium $\left({ }^{3} \mathrm{H}\right)$ labelled $\mathrm{Cp}$ ligands in $\mathbf{1}$ and isolated salmon testes DNA, allowed the average Ti-to-Cp ratio in the resultant DNA adducts to be determined. Reactions at pH 5.3 led to ' $\mathrm{Cp}_{2} \mathrm{Ti}^{\prime}$ ' binding, however, those at (more biologically relevant) $\mathrm{pH} 7$ led to mostly to 'CpTi' adhesion and some (ca. 15\%) non-Cp titanium species. The Ti uptake is rather slow (>2-6 h, pH 5-7 for $10 \mathrm{mM} \mathrm{1}$ ), as monitored by ICPMS, and no information is gained about potential site(s) of binding. ${ }^{12}$ Extraction of the DNA from human ovarian carcinoma cells (A2780), that had been treated with $\mathbf{1}$ ( $1 \mathrm{mM}, 15 \mathrm{~h}$ ), has also been carried out. It was found that it contained $15 \mu \mathrm{g} \mathrm{Ti}$ per gram of DNA isolated. ${ }^{11}$ Individual human cells contain about 7 picograms of DNA implying titanium burdens of only attomols $\left(10^{-18}\right)$ per cell - equivalent to the adhesion of only ca. 1 million molecules of $\mathbf{1}$ to a single cell. The titanium uptake in A2780 is also timedependant, cells treated for 2-6 h show DNA with little more than background levels of titanium. Fitting this 
picture, titration studies of $\mathbf{1}$ with DNA models (e.g. 5'-dGMP) at $\mathrm{pH}$ 7.0-7.4 indicate no binding, just independent hydrolysis of $\mathbf{1}$ in these freshly prepared samples (NMR data at 0-20 h). ${ }^{7}$

The type of cell death induced by $\mathbf{1}$ or other titanium-anticancer agents can also be a hallmark of its mode of action, so these are now briefly overviewed (Figure 3). Depending on the external stimuli provided to the cell (by the anti-cancer, or indeed any other agent) three major forms of programmed cell death (PCD) can occur: apoptosis (type 1), autophagy (type 2) or regulated necrosis (type 3). All three types can be characterised by cellular morphology changes and biochemical/biomolecular alterations (Figure 3). ${ }^{13}$ Apoptosis is the most common form of programmed cell death suggested for $\mathbf{1}$. Apoptotic cells undergo cell shrinkage, membrane blebbing (formation of cell membrane protrusions), DNA chromatin condensation, nuclear fragmentation and formation of apoptotic bodies.

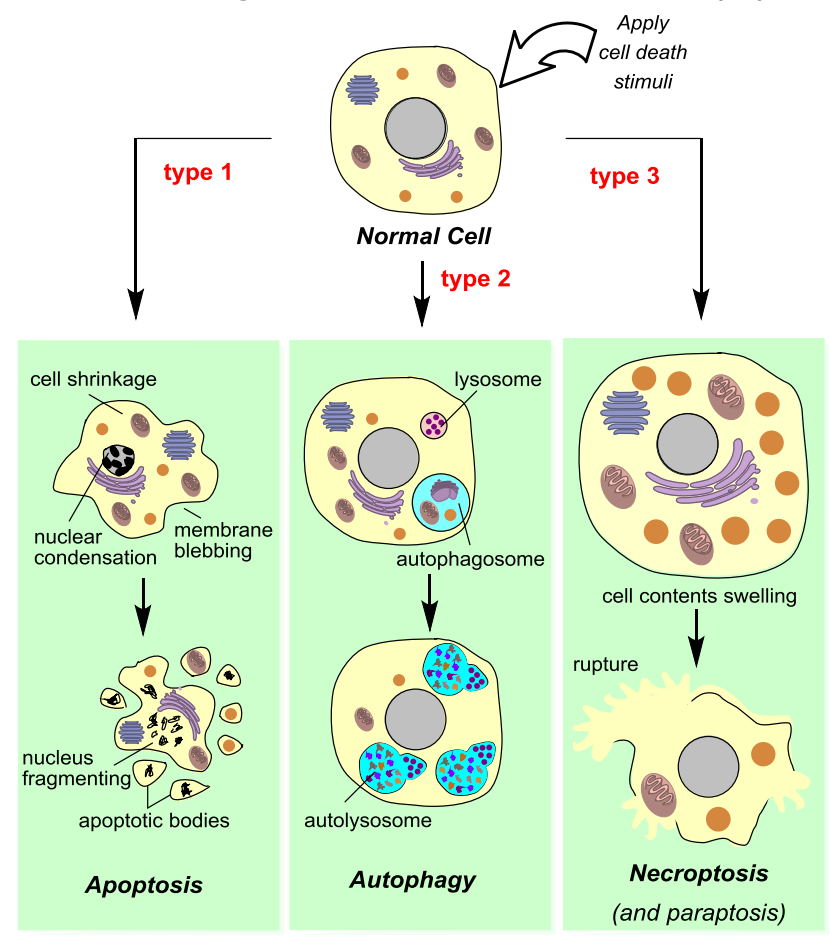

Figure 3. Types of programmed cell death induced by titanium-based agents. Paraptosis is distinct from, but related to necroptosis (type 3 PCD): cellular swelling is caused by extensive formation of intracellular (cytoplasmic empty) vacuoles, represented in part by in the schematic. In more common necrosis only swelling of the cellular organelles is observed [based on ref. 13 and reproduced with permission].

Autophagy (type $2 \mathrm{PCD}$ ) is a self-degradative process of programmed cell death. The initial step in autophagy is the formation of an isolation membrane, a small lipid bilayer membrane structure called a phagophore. The phagophore then expands in order to be loaded with intra-cellular cargo such as protein aggregates, organelles and ribosomes. This results in the formation of an autophagosome, a spherical double-membraned structure containing sequestered cargo. The loaded autophagosome then fuses with a spherical vesicle (lysosome) containing hydrolytic enzyme proteases, resulting in vesicle content degradation. Immunoblotting, immunoprecipitation and/or immunofluorescence analyses of key proteins that interact with the human autophagic machinery (most notably LC3, BECN1 and p62/SQSTM1) can allow detection of autophagy as a possible 'mode of action'. ${ }^{14}$ It has been suggested to be involved for the fluoro analogue of $\mathbf{1}\left(\mathrm{Cp}_{2} \mathrm{TiF}_{2}\right)^{15}$ and in agglomerated $\mathrm{TiO}_{2}$ nanoparticles (diameter $1000 \mathrm{~nm}$ ). ${ }^{16}$

Necroptosis (type 3 PCD). Necrosis is a form of cell death that is morphologically characterised by cellular swelling, rupture of the plasma membrane and loss of cytoplasmic contents. Inflammatory necrotic cell death is normally classified as a non-PCD. However, necrotic PCD is known and termed necroptosis to distinguish it. This PCD is controlled by specific signal pathways and metabolic breakdown of signal molecules. Cytotoxic agents have been reported to induce necroptosis when a cell cannot die via (type 1) apoptotic pathways. Among other related atypical cell death modes of relevance to titanium anti-cancer agents, paraptosis (which can be considered as a form of type 3 PCD), is of importance. It is both morphologically and biochemically distinct from apoptosis (no common morphological hallmarks) and is associated with extensive cytoplasmic vacuolisation and mitochondrial swelling resulting in cell rupture (Figure 3€). ${ }^{17}$ Park reported vacuolisation, dilated $\mathrm{ER}$ and mitochondria in $\mathrm{MH}-\mathrm{S}$ murine alveolar macrophages, by $\mathrm{TiO}_{2}$ nanosheets (ca. $400 \times 400 \times 2 \mathrm{~nm}$ ) and concluded that induced paraptosis and late onset apoptosis were the mechanisms of action. ${ }^{18}$ 
Even for the non-biologist, understanding the mechanistic links between PCD and cell division (the cell cycle) is of fundamental importance in developing effective routes to anti-cancer therapy. For example, cells respond to DNA damage by halting cell cycle progression. During such arrests, the cell 'decides' whether the DNA damage can be repaired. Multiple DNA repair mechanisms have evolved to ensure the integrity of genetic material (breakdown in DNA repair enzymes can predispose individuals to cancer). If DNA damage is extensive, the cells may trigger apoptosis. For example, the p53 gene is a tumour suppressor gene that is activated in response to diverse cellular stresses such as DNA damage, reduced oxygen levels and increased levels of tumour-gene expression. The p53 protein binds to DNA which in turn stimulates production of protein p21 that interacts with cell-division stimulating protein (cdk2). Complexation of p21 and cdk2 halts the cell from passing through the next stage of cell division. If inactivated through mutation p53 is unable to bind to DNA and as a consequence, the p21 protein is not activated and the cells continue to divide uncontrollably to form tumours. ${ }^{19}$ The cell actively halts progression through such cell cycle checkpoints as necessary. For the non-biologist, a simple reminder of the cell cycling process is given in Figure 4.

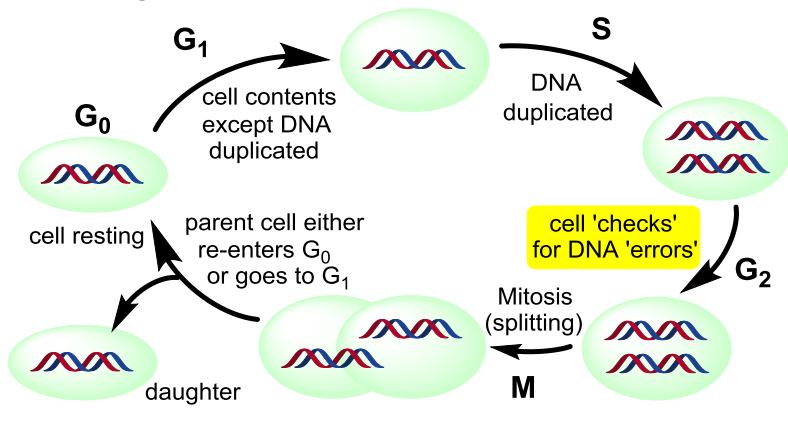

Figure 4. Simplified cell cycling processes. After periods of growth and DNA replication called the interphase (G1+S+G2) nuclear division (mitosis) and cell division (cytokinesis) occurs. The interphase can be further subdivided into three sub-phases. In the G1 sub-phase, cell growth and synthesis of RNA and protein occurs. This is followed by $\mathrm{S}$ sub-phase where DNA synthesis takes place followed by G2, where cells continue to grow and produce new proteins required for cell division.

The effects of anti-cancer titanium agents on the cell cycle can be interrogated by use of propidium iodide (PI) a DNA intercalating dye which fluoresces strongly when bound to DNA. The DNA content of an individual cell is directly proportional to the fluorescence intensity of excited PI. A histogram of the DNA content of cells in a population can be used to ascertain what percentage of cells are in each phase of the cell cycle and how test compounds perturb this. Cells are permeabilised by fixation or through the use of a gentle detergent/hypotonic solution in order to allow the PI entry to the cell (to intercalate its DNA). The sub- $G_{1}$ peak can be used as an indication of the proportion of the total cell population which possess hypoploid§ DNA content indicative of cells undergoing apoptosis. Ovarian A2780 tumour cells treated with $1\left(1 \mathrm{mM}, 1.75 \times \mathrm{IC}_{50}\right)$ showed S block $(+30 \%$ at $15 \mathrm{~h})$ and $\mathrm{G} 2-\mathrm{M}$ block $(+23 \%$ at $24 \mathrm{~h})$. However, at both earlier $(6 \mathrm{~h})$ and later $(48 \mathrm{~h})$ the cell cycle distributions are essentially identical to control cells, implying that the cell recovered to normal cycling after a short period after agent $\mathbf{1}$ exposure. ${ }^{11}$ Interestingly, cell cycle studies at different intervals after agent $\mathbf{1}$ exposure $(6,12,24$ and 48 h) in both prostate cancer cell line PC3 and prostate normal epithelial cell line PWR-1E do not reveal any significant effect on the ratio of $G_{1}, S$, or $G_{2}$ phases of the closely related titanocenes $X$ and $Y$ (2-3, Figure 5) in A431 cells revealed anti-proliferative activity through cell cycle arrest, ultimately resulting in apoptosis. Titanocene $X$ and $Y$ caused $G_{2} / M$ block with a concomitant induction of apoptosis. In contrast, cisplatin treatment of the same cell line results in cell cycle arrest at $S$ phase (inability to duplicate DNA due to cisplatin-DNA induced adducts), further suggesting that the apoptotic effects of 2-3 occurs via alternative mechanisms. ${ }^{20}$
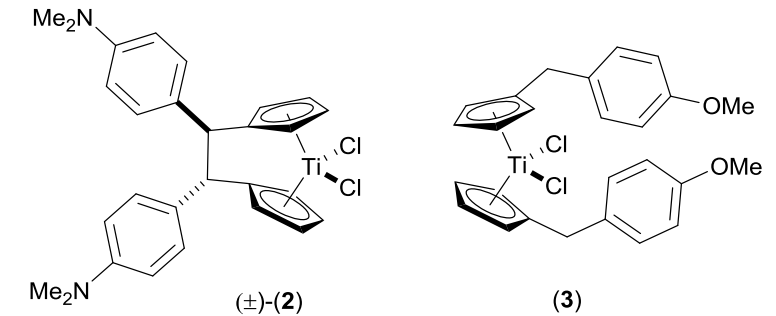

Figure 5. Structures of titanocene-X (2) and titanocene-Y (3). Complex 2 is isolated as a racemic mixture of the rac-diastereomer.

Typically degradation of the cellular constituents initiated by PCD is achieved by a group of caspase enzymes (cysteine proteases) that break down the cellular proteins and peptides. $\neq$ Caspases can be activated through two-distinct but convergent pathways, the intrinsic (mitochondria-mediated pathway) 
and the extrinsic (death receptor-mediated) pathway (Figure 6). Specific transmembrane tumour necrosis factor receptors (TNF) mediate the extrinsic apoptotic route. The binding of (protein) ligands with death receptors initiates the apoptosis cascade. For example, FasR, a death receptor involved in cellular proliferation, differentiation and apoptosis, binds to FasL, its (protein) ligand counterpart, resulting in clustering of the plasma membrane, initiating apoptosis. Caspase 8 can be activated via the Fas-associated death domain protein (FADD). This caspase cleaves the protein BID (a pro-apoptotic protein of the $\mathrm{Bcl}-2$ family) resulting in crosstalk with the intrinsic mitochondrial pathway, thereby amplifying the apoptotic response. Activation of caspases-3, 6 and 7 results in cell death through proteolytic cleavage of diverse cellular targets.

Apoptotic induction of A431 cells by titanocene $Y(\mathbf{3})$ is dose- and time-dependent in caspase-3 and 7. However, no activation was detected for caspase-8. The use of the pan-caspase inhibitor Z-VAD-FMK, a cell-permanent molecule that irreversibly binds to the catalytic site of caspases, prevented apoptotic induction by titanocene $Y$ (3) thus confirming that apoptosis is induced via a caspase-dependent pathway in this case. ${ }^{21}$ However, pre-incubation of PC-3 prostate cancer cells with Z-VAD-FMK failed to block apoptosis caused by $\mathbf{1}$ or titanocene $Y(\mathbf{3})$ at $24 \mathrm{~h} .{ }^{22}$ In order to assess whether titanocene $Y \mathbf{3}$ induced apoptosis by triggering the extrinsic (death receptor-mediated) pathway, the agent was tested against FasR death receptor deficient BJAB lymphoma cells. It was found these cells were more resistant to apoptotic induction by titanocene $Y(\mathbf{3})$ and also showed a substantial increase (upregulation) of the Fas Ligand. This confirmed the role of FasR in the extrinsic cell death pathway. Similarly, MeIHO human melanoma cells (that overexpress a protein that inhibits apoptosis, anti-apoptotic Bcl-2) were also utilised to elucidate the role of the $\mathrm{Bcl}-2$ protein in titanocene $\mathrm{Y}$ (3) apoptotic induction. However, it was found that apoptosis was triggered regardless of the expression of anti-apoptotic Bcl-2. ${ }^{23}$

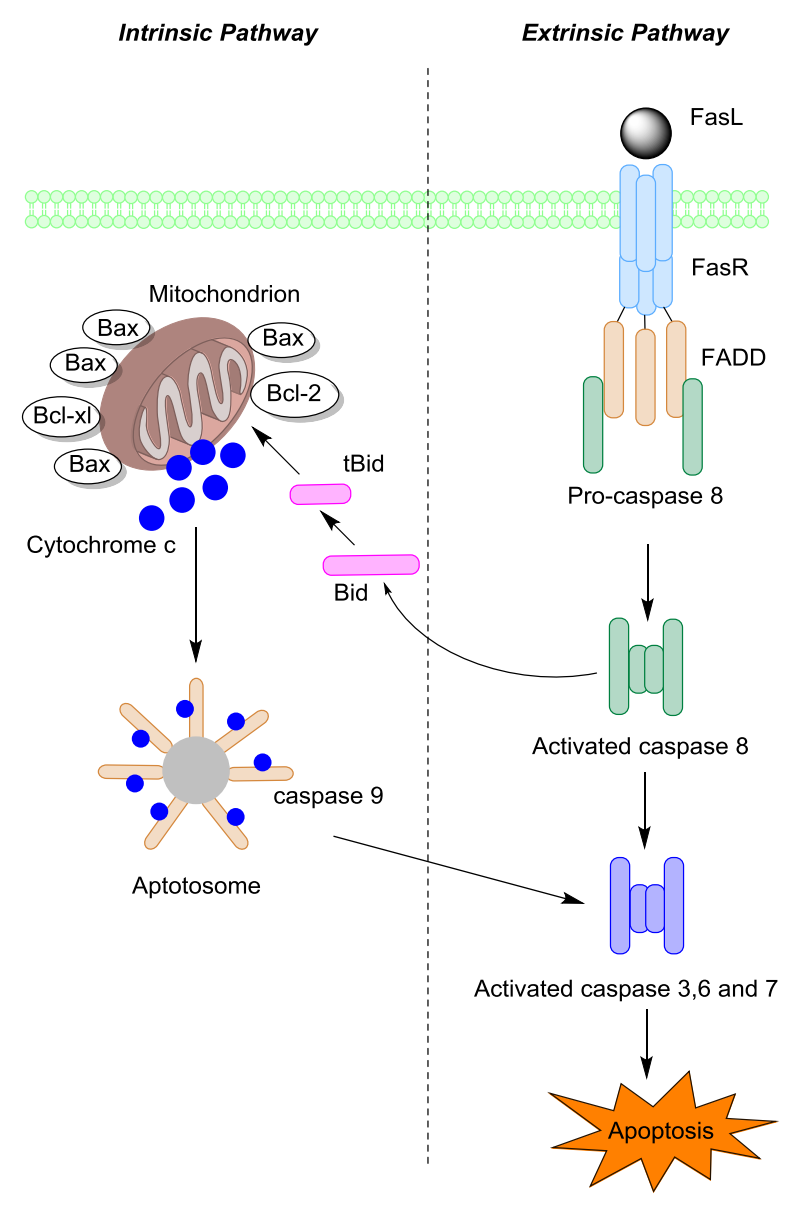

Figure 6. Activation of caspases (cysteine proteases) by the extrinsic and intrinsic apoptotic pathways. The circles ( $)$ indicate activating proteins [based on ref. 13 and reproduced with permission].

In the early stages of apoptosis, plasma membrane cell surface changes result in the translocation of the phospholipid phosphatidylserine (PS) from the inner side to the outer layer of the plasma membrane (Figure 7). Thus, PS becomes exposed at the external surface of the cell. The Ca ${ }^{2+}$ dependent phospholipid binding protein Annexin $\mathrm{V}$ has a high affinity for PS, thus can be utilised as a sensitive probe for PS exposure at the external surface of the cell. During the initial stages of apoptosis, the cell membrane remains intact but later, the cell membrane loses its integrity and becomes 'leaky'. Therefore, the stages of cell death can be determined by flow cytometry using Annexin $\mathrm{V}$ as a measurement of cell surface binding in conjunction with a dye exclusion test (e.g. fluorescent dyes such as propidium iodide, 
PI) that determines whether cell membrane integrity is lost. Thus, apoptotic (dying) or necrotic cell populations can be distinguished from healthy cells, which do not bind Annexin V and exclude PI. ${ }^{24}$
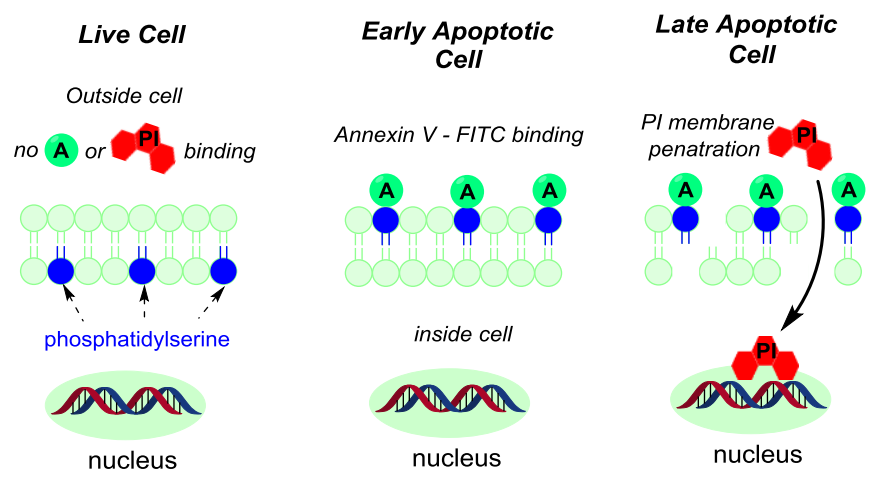

Figure 7. Flow cytometry methods to distinguish between cells cycling normally and those entering apoptosis and dying by this route.

\section{Recent findings in titanium anti-cancer 'mode(s) of action'}

Hydrolysis of $\mathbf{1}$ and its simple derivatives to protein-bound 'ligandless' Ti-species seems to offer a straight forward process for the delivery of titanium into the cell (where its death is subsequently triggered). In an attempt to avoid the hydrolytic complexity of $\mathbf{1}$ Valentine $^{25}$ and Tshuva ${ }^{2}$ introduced the use of multidentate complexes of the type 4-5 (Figure 8). These species are rather more persistent in aqueous solution and their behaviour is not in accord with the involvement of the serum proteins Tf or SA as titanium transport vectors into the cell.

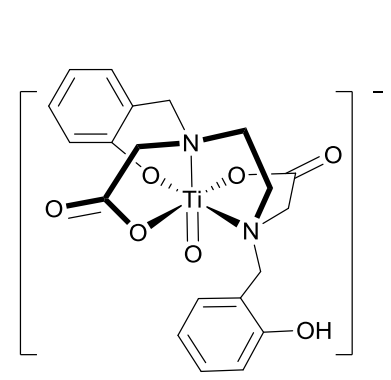

(4)

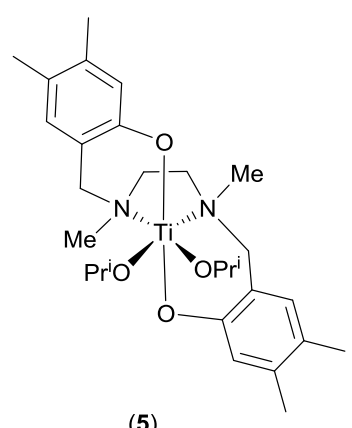

(5)

\begin{tabular}{cccc} 
Compound & $\begin{array}{c}\text { Cell line } \\
\text { (exposure time) }\end{array}$ & $\begin{array}{c}\mathrm{IC}_{50} \\
\text { compound } \\
\text { alone, } \mu \mathrm{M}\end{array}$ & $\begin{array}{c}\mathrm{IC}_{50} \mu \mathrm{M} \\
\text { when }(+ \text { serum } \\
\text { protein } \mu \mathrm{M})\end{array}$ \\
\hline $\mathrm{Cp}_{2} \mathrm{TiCl}_{2}$ (1) & $\mathrm{HT}-29(3 \mathrm{~h})$ & 710 & $460(+\mathrm{Tf}, 0.1)$ \\
$\mathrm{Cp}_{2} \mathrm{TiCl}_{2}$ (1) & OVCAR-1 (3 h) & 780 & $520(+\mathrm{Tf}, 0.1)$ \\
Titanocene Y (3) & $\mathrm{MCF}-7$ (5 d) & inactive & $\sim 10(+\mathrm{BSA}, 0.8)$ \\
$(\mathbf{4})$ & $\mathrm{A} 549(3 \mathrm{~d})$ & 25 & $43(+\mathrm{Tf}, 30)$ \\
$(\mathbf{4})$ & $\mathrm{A} 549(3 \mathrm{~d})$ & 25 & $33(+\mathrm{SA}, 600)$ \\
$(\mathbf{5})$ & $\mathrm{HT}-29(3 \mathrm{~h})$ & 12 & $16(+\mathrm{Tf}, 0.1)$ \\
$(5)$ & OVCAR-1 (3 h) & 14 & $15(+\mathrm{Tf}, 0.1)$ \\
\hline
\end{tabular}

Normal human serum protein levels are: $\mathrm{Tf} \sim 35 \mu \mathrm{M}$; SA $\sim 640 \mu \mathrm{M}$ BSA is bovine serum albumin

Figure 8. Effects of the serum proteins transferrin (Tf) and serum albumin (SA) on complexes 1 and 35. Studies were carried out at $37{ }^{\circ} \mathrm{C}$ with $\mathrm{IC}_{50}$ error bars of typically $\pm 15-20 \%$ of the values reported above. ${ }^{1-2,7,25}$

Unlike (1) and titanocene Y (3), complex 4 actually became less effective in the presence of physiological concentrations of Tf and SA [A549 cell line]. Similar, but less pronounced, behaviour was found for $\mathbf{3}$ [HT-29 and OVCAR-1 cell lines] albeit at much lower apo-transferin concentrations. Although for metallocenes $\mathbf{1}$ and $\mathbf{3}$ anti-cancer activity is apparently increased by both Tf and SA - the concentrations used in the experiments of Figure 8 are well below physiological values. Complex 4 has been shown to be unstable with respect to metal exchange with iron(III) citrate at $\mathrm{pH}$ 7.4. Citrate serves as a significant non transferrin iron binder in human serum and is present at $\sim 100 \mu \mathrm{M}$. This implies that 4 can act as an Fe(III) scavenger and this might adversely affect cancer cells disproportionately due to their greater metabolic iron requirement. ${ }^{26}$ In comparison to $\mathbf{4}$, compound $\mathbf{5}$ shows higher stability. 
The fact that hydrolysis of $\mathbf{1}$, and related metallocenes, generate macroscopic insoluble Ti-based particulates (especially at longer time periods, days) can allow an alternative mechanism for titanium uptake/signalling via cellular particle envelopment (phagocytosis). Using model 20-30 $\mathrm{nm} \mathrm{TiO}_{2} \mathrm{spheres}$ Rashkow showed a Gaussian distribution of titanium burdens within SK-BR-3 breast cancer cells with an average of 26 picomol Ti/cell after exposure (range 0-1.7 nanomol/cell). ${ }^{27}$ Interestingly, none of the resulting intracellular $\mathrm{TiO}_{2}$ particulates (100-8000 nm in size) become associated with the nucleus but some are present in intracellular vacuoles. Studies of related 'sheet-forms' of $\mathrm{TiO}_{2}$ of dimensions $400 \times 2$ $\mathrm{nm}$ also induced the formation of vacuoles and triggered both paraptosis and apoptosis in mouse-derived white blood lung cells (MH-S) when so treated $\left(24 \mathrm{~h}, 10-20 \mu \mathrm{g} \mathrm{ml}^{-1}\right.$, effective equivalent Ti concentration 0.1-0.2 $\mu \mathrm{M}$; but only $20 \%$ growth inhibition was attained). ${ }^{18}$ Interestingly, larger $\mathrm{TiO}_{2}$ spheres ( 1000 nM diameter) do not induce paraptosis.

One potential way to answer the question: "what causes the biological activity - true homogeneous titanium complexes or heterogeneous (and potentially ligandless) precipitates?" is through the use of chiral titanium complexes. Because of innate stereo-discrimination in biological receptors enantiomer dependent biological outcomes if triggered by truly homogeneous species, but not if hydrolysis and/or precipitation has taken place. In principle, the same approach is applicable to both titanocene dichloride complexes or heteroatom ligated Ti(IV) complexes as in the examples of Figure 9. Enantiopure titanocene dichlorides, that also demonstrate significant anti-cancer activity, are limited to (6) attained through asymmetric catalysis. ${ }^{28}$ The $(S, S)$ enantiomer of 6 is significantly more cytostatic to MDA-MB-468 cells $\left(\mathrm{GI}_{50} 11 \mu \mathrm{M}, 24 \mathrm{~h}\right)$, than $(R, R)-(\mathbf{6})$ which delivers weaker growth inhibition $\left(\mathrm{GI}_{50} 23 \mu \mathrm{M}\right)$ under the same conditions. This complex triggers cell death by paraptosis (see Section 2) in the same the same cell line and timeframe and its biological activity correlates strongly with the formation of spectroscopically characterised $\left[\mathrm{Cp}_{2}{ }_{2} \mathrm{Ti}(\mathrm{OH})\left(\mathrm{OH}_{2}\right)\right]^{+}$cations $\mathrm{Cp}^{\mathrm{R}}=\mathrm{C}_{5} \mathrm{H}_{4} \mathrm{CHEt}\left(2-\mathrm{MeOC}_{6} \mathrm{H}_{4}\right)$. This species undergoes further hydrolysis to insoluble partially characterised $\left[\mathrm{Cp}^{\mathrm{R}}{ }_{2} \mathrm{Ti}=\mathrm{O}\right]_{\mathrm{n}}$ species. The latter is also biologically active $\left(\mathrm{GI}_{50} 5.5 \mu \mathrm{M}\right.$ against MDA-MB-468) but this is independent of the enantiomer of 6 used at $72 \mathrm{~h}$ exposure. ${ }^{28}$ One explanation is that the later activity is related to the 'heterogeneous' anti-cancer activity shown by sheet $\mathrm{TiO}_{2}$ (see above ${ }^{18}$ ). The chiral 'salan-based' complexes of Tshuva and Manna show equally intriguing behaviour. ${ }^{29}$ The separate enantiomers of (7) show almost equipotency (IC $50 \sim 5 \mu \mathrm{M}, 72$ h) against HT-29 cells but a racemic (1:1) mixture of the same complexes is inactive against the same cell line. Complex $(R, R)-\mathbf{8}(\mathrm{Y}=\mathrm{Br})$ shows similar behaviour, but for closely related $\mathbf{7}(\mathrm{Y}=\mathrm{H})$ the $(S, S)$ enantiomer is significantly more active [ $\mathrm{IC}_{50} 39 \mu \mathrm{M}$ vs. HT-29] than its $(R, R)$ isomer [IC $50154 \mu \mathrm{M}$ vs. HT29]. Diastereospecific formation of dimeric (as in Figure 7), or even trimeric species, that are the putative active anti-cancer agents have been suggested to account for the behaviour of (7-8). Fitting this picture those 'salan-based' complexes that are the most hydrolytically stable often exert the poorest biological performance. The inactivity of the isolated dimers (e.g. 9) was not at all consistent with such pictures. However, this appears to be an artefact caused by their poor aqueous solubility - when formulated as colloidal suspensions (average diameter $18 \mathrm{~nm}$ ) activity against HT-29 was re-established [IC ${ }_{50} 13 \mu \mathrm{M}$ ].

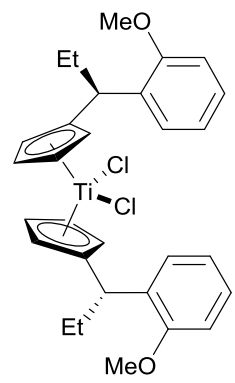

$(S, S)-(6)$

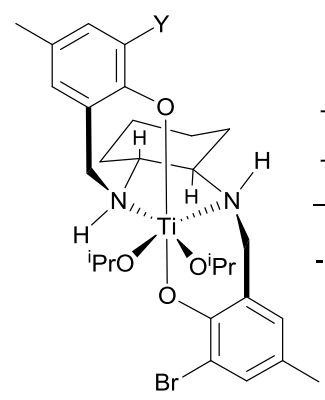

$(R, R)-(8)$

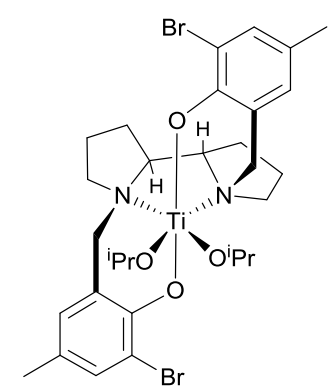

$(S, S)-(7)$

$$
\begin{gathered}
+(R, R)-8 \\
\text { or... } \\
+(S, S)-8
\end{gathered}
$$

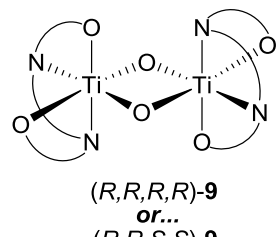

$(R, R, S, S)-9$

(ligands shown schematically)

Figure 9. Representative enantiopure titanium complexes. 
In 2009 Huhn reported that 10-11 were able to induce high cytotoxicity toward cervix tumour HeLa S3 cells (Figure 10$).{ }^{30}$ Highly selective apoptotic (>95\%) induction was attained for 10, whereas necrosis accounted for $\sim 50 \%$ cell death with 11. Salan-based-Ti ${ }^{\mathrm{IV}}$ complexes of formula 12 were also reported to be highly active against various tumour cell lines but also against cisplatin-resistant human ovarian cancer cell lines (A2780CisR) and multi-drug resistant (ABCB1-expressing) mouse lymphoma cell lines $\mathrm{HU}-1$ and $\mathrm{HU}-2$. Such findings suggest that salan-based complexes are unaffected by cisplatin/multi-drug resistance mechanisms, and may provide further evidence against direct DNA coordination by such Ti(IV) complexes. Analyses of the cell cycle distribution after $\mathrm{LTi}(\mathrm{O} i \mathrm{Pr})_{2}$ agent addition on $\mathrm{T}-25$ lymphoma cells evidenced a greater percentage of treated cells accumulated at the $\mathrm{G}_{1}$ stage. This result was linked to upregulation of the tumour suppressor protein p53 (the growth regulator protein that protects against cellular damage, see Section 2). A significant increase of p53 levels in the T-25 cells was observed following incubation with $\mathrm{LTi}(\mathrm{O} i \mathrm{Pr})_{2}$. An apoptotic pathway was further supported via positive Annexin $\mathrm{V}$ early apoptotic binding. ${ }^{31}$

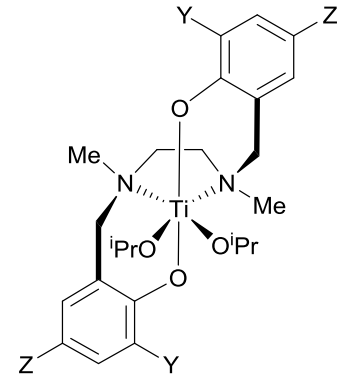

(10) $Y, Z=C l$

(11) $Y, Z=M e$

(12) $\mathrm{Y}=\mathrm{Cl}, \mathrm{Z}=\mathrm{Me}$

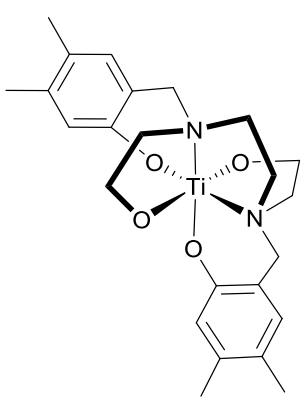

(13)

Figure 10. Recent (2009-2016) highly active 'salan-based' titanium complexes.

Cell cycle arrest at $\mathrm{G}_{1}$ was observed in both HT-29 and $\mathrm{A} 2780$ cell lines following $\mathrm{LTi}(\mathrm{O} i \mathrm{Pr})_{2}$ addition, suggesting an alternative mechanism of action compared to that of $\mathbf{1}$ (cell cycle mostly unaffected) and titanocene $Y(\mathbf{3})$, which blocked cells at the $G_{2} / M$ phase. Following incubation with $\mathrm{LTi}(\mathrm{O} i \mathrm{Pr})_{2}$, a significant increase in the p53 levels was observed in both cell lines whilst p21 was only detected in A2780 cells. Cleaved caspase 9 was also detected in both cell lines suggesting a caspase-dependent apoptotic pathway. Cellular accumulation of titanium in HT-29 and A2780 cells evidenced a gradual increase in accumulation in both cell lines as a function of agent incubation time. Comparison of the activity of $\mathbf{1 3}$ against the NCI-60 cell line panel reveals a unique profile suggesting that the mechanism of action of the titanium complex is distinct, and is not reflected in existing anti-cancer agents. ${ }^{32}$ Finally, direct comparison of titanium $Y$ (3) and 'salan-based' complexes indicates that their mechanisms of action are different in MCF-7 and HT-29 cell lines. For Ti-Salan-based species experiments revealed a slow but steady accumulation of titanium in the mitochondria after extended exposure (24 h). On the other hand, intracellular experiments following titanocene $Y$ (3) exposure revealed only low levels thereby indicating that the bio-distribution of Ti in the cells is dependent on the Ti(IV) complex. ${ }^{33}$ Such studies indicate that bio-physical studies, while vital, can only provide a partial picture in such biochemically complex systems and that use of the full range of modern synthetic biology tools need to be deployed to provide comprehensive understanding. For this reasons both of these are overviewed in context next.

\section{Contemporary tools for determining titanium 'mode(s) of action'}

In biology, a mode of action describes a functional or anatomical change, at the cellular level, resulting from the exposure of cells or a living organism to a test agent or drug. In comparison, a mechanism of action describes perturbations at the molecular level. Initial light, bright field, fluorescence, microscopy, to determine morphological changes wrought by treatment of cells with test agents is a critical step and the first indication that agent under scrutiny is having an observable effect on cells. For example, the early observation of Köpf-Maier showing that Ehrlich ascites cells, following treatment with 1, underwent dramatic swelling although strongly indicative of necroptosis/paraptosis remained largely uncommented upon. $^{3}$ Recent developments in instrumentation allow easier identification of cellular modes of activation. ${ }^{28}$ Modern confocal and super-resolution microscopy ${ }^{34}$ can be utilised to probe mechanisms of action for example, individual $\mathrm{YH} 2 \mathrm{AX}$ foci (visible sites of DNA damage) can be defined at areas of DNA double strand breaks but are not always informative, e.g. in Tinoco's studies the morphology of A549 was unaffected by treatment with $\mathbf{4 .}^{25}$ Although higher resolution electron microscopy (scanning, transmission) is able to resolve cellular organelles in fine detail current associated EDAX detectors are not sensitive enough for titanium detections at the very low levels present in cells. Synchrotron-induced 
fluorescence offers better opportunities - but exact quantification is an issue. As seen in Section 2 , through cells labelled with different fluorochromes flow cytometry (FC) offers the simplest way to attain multiparameter analysis of different cellular components or processes on a cell-by-cell basis. A number of analyses may be performed by flow cytometry including determination of cell cycle distribution, apoptosis, $\mathrm{yH} 2 \mathrm{AX}$ quantification and reactive oxygen species generation in routine experiments easily carried out by chemical scientists. ${ }^{34-37}$

When faced with a test agent whose activity has been validated, yet whose mechanism of action is unknown a number of interrogative techniques are available, some of which are briefly discussed here. Reacting to the explosion in kinase inhibitor research, high-throughput (HTP) kinase profiling has been developed by many organisations. The activity of hundreds of kinases can be compared in lysates of compound- and vehicle-treated cells. Alternatively, cell-free assays offer the opportunity to determine the effect of a given compound on activity of hundreds of kinases. Screens utilise a number of techniques including radiometric and time-resolved fluorescence energy transfer (TR-FRET) analyses. ${ }^{38,39}$ The latter, a combination of time-resolved fluorometry (TRF) and Förster resonance energy transfer (FRET) offers a powerful tool for drug discovery researchers. To validate HTP assays, determination of phosphorylation should be conducted (e.g. Immunoblot profile kits or Western blot as outlined below). Custom screening options are available, in which kinases under investigation and compound concentrations can be selected by the researcher, allowing dose-response and IC $_{50}$ profiles to be generated. The ATP binding site is a common target for kinase inhibitors and thus ATP competition assays can be provided.

Traditionally, proteomics (protein analysis) methodologies have relied upon separation of complex protein mixtures in samples by 2-dimensional gel electrophoresis: by isoectric point and molecular weight. ${ }^{40}$ Patterns could be compared, and where changes were evident, protein identification involved isolation of protein spots, proteolysis, and mass analysis of each peptide prior to sequence database searched. Multidimensional Protein Identification Technology (MudPIT) eliminates the need for gel electrophoresis. Biochemical fractions/cell lysates containing many proteins are directly proteolysed and the enormous numbers of peptides generated are separated by 2-dimensional liquid chromatography. Tandem mass spectrometry (LC-MS/MS) is then employed to identify those proteins whose expression has been up- or down-regulated by the test agent. ${ }^{41}$

Attaining the identity of the exact titanium entity responsible for a specific biological observation is a major challenge as hydrolysis of the precursor complexes typically occurs in the same time frame and distinguishing between soluble and insoluble species has been a recurrent problem in this area. Even in the case of species stable to ligand $\operatorname{loss}^{29}$ aggregation effects might occur and anti-cancer activity triggered by heterogeneous species is also known. ${ }^{18}$ Electrospray (ESI) analyses of the complex pro-drug dissolved in its cellular growth medium can provide a way to estimate the total Ti-species present as a function of time. If, in the same time frame, LCMS studies are also carried out disambiguation of solution vs insoluble species can be attained in favourable cases, as the latter are not eluted in the LCMS. For 6 pairing such analyses confirmed formation of homogeneous $\left[\mathrm{Cp}^{\mathrm{R}} \mathrm{Ti}(\mathrm{OH})\left(\mathrm{OH}_{2}\right)\right]^{+}$was commensurate with the onset of paraptosis. ${ }^{28}$ Disappearance of the latter led to the formation of insoluble precipitates, observed as protonated $\left[\mathrm{Cp}_{2}^{\mathrm{R}}{ }_{2} \mathrm{TiO}\right]_{2}$. Once identified this process could be kinetically modelled with high confidence, even though both the starting $\mathbf{6}$ and it eventual product are insoluble under aqueous conditions. Kinetic modelling of titanium speciation should be a powerful tool for identifying potential biologically active species - particularly if matched against the onset of biological outcomes. However, as the concentrations of the titanium species involved in real biological systems are low ( $\mu M)$ use of NMR has only recently become practical with the widespread availability of very high field $(>600 \mathrm{MHz})$ instruments.

A powerful tool which facilitates identification of protein targets of aqueous titanium species is offered by genome-wide short hairpin RNA (shRNA) library screens. Whole genome-, custom- and kinase-pooled lentiviral library screening is possible. In this technique, cells are transduced with human pooled shRNA library which may target $>15000$ human genes. Transduced cells are selected by survival in medium supplemented with antibiotic (e.g. $1 \mu \mathrm{g} / \mathrm{mL}$ puromycin; 4 days) before being treated with test agent (e.g. for $72 \mathrm{~h}$ ). Following isolation of genomic DNA, ShRNA sequences present in each sample are determined by next generation sequencing (NGS). ${ }^{42,43}$ Data are screened and analysed for parallel sequencing. A shRNA kinase pool has been developed which targets the human kinome and contains within the library 745 genes commonly associated with development and disease, with an average of 12.6 shRNA clones per unique kinase gene. Enrichment, depletion and non-target controls are necessary to allow confidence in results. This method allows HTP screening of hundreds of genes (and kinases) to aid identification of genes essential for test agent activity/resistance.

Upon identification of putative molecular targets and mechanisms of action, it is imperative to perform experiments to validate the findings. Quantitative polymerase chain reaction (qPCR) also known as real-time $P C R$, is a molecular biology technique to amplify and simultaneously quantify a specifically involved DNA sequences/genes. ${ }^{44}$ Thus, this technique can be used to validate a microarray experiment which indicated 
that treatment $X$ resulted in up-regulation of gene $Y$ expression. Expression of gene(s) to be measured by qPCR require specific primers (short nucleic acid sequences typically 10 base pairs long) because the DNA polymerase enzymes that catalyse qPCR are only able to add nucleotides to existing DNA strands. The technique can generate thousands of copies of a single DNA sequence; expression data generated should always be normalised to a house-keeping gene (e.g. GAPDH). To determine whether up-regulation of gene $Y$ translated to enhanced protein $Y$ expression, or to validate proteomic techniques such as MudPIT, Western blot experiments may be performed. Proteins from whole cell lysates are separated by polyacrylamide gel electrophoresis (PAGE) and proteins electroblotted onto nitrocellulose or polyvinylidene difluoride (PVDF) membranes. ${ }^{45}$ Protein binding to membrane is a consequence of hydrophobic and charged interactions between membrane and protein. To pursue detection of a specific protein of interest, non-specific binding of antibodies to the membrane must first be blocked (typically using 5-10\% dried milk in tris-buffered saline). Sequential incubation of membrane with primary antibody $\left(1^{\circ} \mathrm{Ab}\right)$ raised artificially to recognise the protein of interest and $2^{\circ} \mathrm{Ab}$ (directed at the species-specific portion of the $1^{\circ} \mathrm{Ab}$ ). The secondary antibody can be linked to a reporter enzyme such as horseradish peroxidase. A horseradish peroxidase-linked secondary is used to cleave a chemiluminescent agent, the reaction product produces luminescence in proportion to the amount of protein. To validate results of a kinase profile array or to interrogate activation of a particular signal transduction cascade, $1^{\circ}$ Abs recognising phosphorylated substrate can be used to measure protein phosphorylation. Levels of phosphorylated and total protein expression should be compared through use of $2^{\circ}$ Abs conjugated to enzymes for colourimetric or chemiluminescent detection.

Finally, to validate the role of (a) protein(s) in the mechanism of action of, or mediation of resistance to test agents, gene transfection or knock-out (KO) techniques can be employed. Transfection is the non-viral deliberate introduction of genetic material [e.g. supercoiled plasmid DNA, small interfering RNA (siRNA)] protein or antibody into eukaryotic cells. ${ }^{46}$ Transfection of exogenous DNA into cells results in an isogenic cell line in which the protein of interest is expressed i.e. the only difference in the parent and its isogenic cell line partner is expression of gene under scrutiny. Conversely, transfection of siRNA into cells can lead to the knocking down of a gene of interest. The siRNAs used are 21-25 base pair double stranded RNA with dinucleotide $3^{\prime}$ overhangs designed to be complementary to the mRNA of a target gene. One strand of the siRNA (the guide strand) complexes with a RNA-induced silencing complex (RISC). This complex then binds to complementary mRNA in the cell and cleaves it. This prevents translation of the target gene so the target protein is knocked down once the cell has turned over all previously synthesised protein. The knockdown achieved is transient, lasting typically between 3 and 7 days. To achieve stable knock-down, lentiviral short hairpin RNA constructs (sh RNA, introduced previously) may be transfected into cells. The isogenic cell lines generated, possessing either transfected protein or silenced gene, provide important tools in elucidation of molecular mechanisms of action and resistance. Subsequent analyses of cellular responses, following interrogation of isogenic cell lines with test agent allows determination of protein function. ${ }^{47}$ Gene targeting is a genetic technique that uses homologous recombination (HR) to permanently alter an endogenous gene. The targeting construct, containing (parts of) the gene to be modified, reporter gene and selectable marker, is generated in bacteria. This procedure may be used to delete a gene, add a gene, introduce genetic point mutations or splice variant genes. It enables creation of isogenic disease models facilitating development of personalised medicine particularly in the field of cancer. ${ }^{48}$

The use of CRISPR Cas9-gRNA complex for genome editing was the American Association for the Advancement of Science's choice for breakthrough of the year in $2015 .{ }^{49}$ Clustered regularly interspaced short palindromic repeats (CRISPR) are segments of prokaryotic DNA containing short repetitions of base sequences. Each repetition is followed by short segments of "spacer DNA" from previous exposures to a bacteriophage virus or plasmid. The CRISPR/Cas system is a prokaryotic immune system that confers resistance to foreign genetic elements such as those present within plasmids and phages, and provides a form of acquired immunity. CRISPR associated proteins (Cas) use the CRISPR spacers to recognise and cut these exogenous genetic elements in a manner analogous to RNA interference in eukaryotic organisms. Cas9 was the first nuclease discovered, CRISPR/C2c2 from the bacterium Leptotrichia shahii is an RNA-guided CRISPR system that targets RNA rather than DNA, and can either cleave single-stranded RNA targets or knock them down. By delivering the Cas9 nuclease complexed with a synthetic guide RNA (gRNA) into a cell, the cell's genome can be excised at a desired location, allowing existing genes to be removed and/or new ones to be added. CRISPR/Cas genome editing techniques have many potential applications, including validation of molecular mechanisms of action of drug candidates.

The procedures outlined above are not exhaustive, but provide initial insight into experiments which may be undertaken, and sophisticated techniques which are available to enable elucidation of molecular mechanisms of action of experimental agents, drug candidates and clinical agents. Indeed, the complex genome-wide functional screens introduced, which warrant further reading to impart deeper understanding, have recently led to identification of genes and proteins affecting sensitivity to tamoxifen, a long-established anticancer drug. ${ }^{50}$ Genomic approaches maybe particularly profitable in the area of titanium-based anti-cancer agents as, to the best of our knowledge, there is not a reported incidence of cellular resistance developing in cell lines exposed to such agents, a clear distinction from Pt-based agents. 


\section{Conclusions: future paths and strategies for titanium therapeutics}

It can be concluded from this review that early ideas that titanium dichloride (1), and other related species, would function analogously to cisplatin were far from the 'complete' truth. To date about 10 variously distinct mechanisms of action have been proposed for titanium-based therapeutics including: the triggering of apoptosis via DNA binding, inhibition of mitochondrial activity, induction of paraptosis (via kinase activation), the inactivation of topoisomerases and cell death by iron deprivation. It is also clear that heterogeneous particulates (nanoparticles), long assumed to be 'unimportant' decomposition products of the homogeneous titanium complexes provided to the cell actually can trigger a wide range of biological outcomes in their own right. Although the presence of such multiple biological activation modes makes understanding the exact behaviour of titanium-therapeutics challenging current chemical and biochemical tools are now available making this a tractable proposition. In fact, opportunities to target multiple mechanisms of action are to be welcomed as they offer potential to tract heterogeneous disease by targeting multiple therapeutic pathways, thus improving clinical outcomes.

\section{Abbreviation list}

BECN1

BID

Cdk2

CRISPR

dGMP

FADD

FasL

FasR

FC

LC3

MTT

MudPIT

p62/SQSTM1

PAGE

PCD

PDVF

PI

PS

qPCR

SA

ShRNA

siRNAs

Tf

TNF

TR-FRET

Z-VAD-FMK
An important $60 \mathrm{kDa}$ signalling protein in autophagy and other PCD events.

A $22 \mathrm{kDa}$ signalling protein that stimulates release of cytochrome $\mathrm{c}$ from the mitochondria.

Cyclin-dependent kinase 2, a ca. 33 kDa protein involved in cell cycle (G1) regulation.

Clustered regularly interspaced short palindromic repeats: DNA containing short repetitions of base sequences that, ultimately, the cell's genome can be cut at a desired location, allowing existing genes to be removed and/or new ones added.

Deoxyguanosine monophosphate, a derivative of the common nucleic acid guanosine triphosphate (GTP).

A $23 \mathrm{kDa}$ adaptor (modifies signalling) protein involved in apoptotic triggering.

The transmembrane ligand protein that binds FasR activating it.

A cell surface bound protein which on ligand binding can trigger apoptosis.

Flow cytometry: Fluorescently labelled cells can be detected, counted and sorted by automated laser detection allowing rapid analyses of cell states and populations.

Microtubule-associated protein light chain 3, a marker protein for autophagosomes.

The dye 3-(4,5-dimethylthiazol-2-yl)-2,5-diphenyltetrazolium bromide.

Multidimensional Protein Identification Technology: a combined chromatography-MS technique for detecting proteins.

A ubiquitin-binding protein mediating selective autophagy.

Polyacrylamide gel electrophoresis.

Programmed (as opposed to accidental) cell death.

Polyvinylidene difluoride, [CH2CF2]n.

The fluorescent DNA intercalator propidium iodide.

Phosphatidylserine: a phospholipid and component of the cell membrane.

Quantified polymerase chain reaction.

A non-specific $66 \mathrm{kDa}$ binding protein for many (small molecule) biological signalling compounds

Short hairpin RNA: used to silence target gene expression.

Small interfering RNA: used to induce short term silencing of protein coding genes.

The 79.6 kDa protein controlling biological iron concentration by Fe(III) binding.

Tumor necrosis factor: a group of cytokines (5-20 kDa signalling proteins) that can trigger apoptotic cell death.

Time-resolved fluorescence energy transfer: allowing the proximity of two appropriate fluorophores to be detected.

Carbobenzoxy-valyl-alanyl-aspartyl-[O-methyl]-fluoromethylketone - a global caspase inhibitor that irriversibly binds to the catalytic site. 


\section{Acknowledgements}

We are deeply indebted to all of the recent key contributors in this area (the 'titans' of the title) many of whom were kind enough to respond to our many questions and offer, in some cases unpublished insights, into the many facets of anti-cancer titanium agents.

\section{Notes and references}

† The US National Cancer Institute (NCI) 60 drug screen compares the anti-cancer activity of a given compound against 60 carcinomer cell lines from nine organ sites that acts as a 'finger print' of the agent's mechanism of action (even if it is unknown).

It is accessed via the web: https://dtp.cancer.gov/discovery development/nci-60/

Over 140 titanium species had been screened by 2016 and their effect vs. the 60 separate cell lines. It provides clear evidence that titanium agents behave differently to the cisplatin family of drugs. For a recent application of such 'COMPARE' algorithm approaches, see ref. 32.

\# The difference between $\mathrm{IC}_{50}$ and $\mathrm{GI}_{50}$ is most easily seen by example. Consider a colony of 20 tumour cells which untreated propagate to 100 cells (after time $t$, control). Against this control the concentration of agent that provides a population of 50 in the same time would be the IC 50 . As the total growth of the colony is (in this case) $100-20$, the $\mathrm{GI}_{50}$ would be the concentration of agent resulting in 60 cells $(80 / 2+20)$ here. Such GI $_{50}$ values are more useful for cytostatic (inhibiting) vs. cytotoxic (killing) agents.

Е A short video clip of MDA-MB-468 (breast) cancer cells undergoing paraptosis is available as Electronic Supporting Information (ESI), see also reference 28.

$\S$ Having a chromosome number that is lower than the normal chromosome count for the species.

* Although caspase independent apoptosis is also known, this is not discussed here as it has not (yet) been implicated in titanium-based anti-cancer agents to the best of our knowledge.

1 For previous overviews of 'titanocene'-based therapeutics see the references within and citations of: K. Strohfeldt and M. Tacke, Chem. Soc. Rev., 2008, 37, 1174.

2 For a previous overviews of 'salan-based'-based therapeutics see the references within and citations of: E. Y. Tshuva and J. A. Ashenhurst, Eur. J. Inorg. Chem., 2009, 2203.

3 All of the key result of the early Köpf and Köpf-Maier period are nicely summarised in their key review: P. Köpf-Maier and H. Köpf., Struct. Bonding, 1988, 70, 105.

4 J. B. Waern, H. H. Harris, B. Lai, Z. H. Cai, M. M. Harding and C. T. Dillon, J. Biol. Inorg. Chem., 2005, 10, 443.

5 J. H. Toney and T. J. Marks, J. Am. Chem. Soc., 1985, 107, 947.

6 M. Guo, Z. Guo and P. J. Sadler, J. Biol. Inorg. Chem., 2001, 6, 698.

7 A. Vessières, M.-A. Plamont, C. Cabestaing, J. Claffey, S. Dieckmann, M. Hogan, H. Müller-Bunz, K. Strohfeldt and M. Tacke, J. Organomet. Chem., 2009, 694, 874.

8 G. Lally, A. Deally, F. Hackenberg, S. J. Quinn and M. Tacke, Lett. Drug Des. Discov. 2013, 10, 675.

9 This early work is summarised succinctly in: A. M. Pizarro, A. Habtemariam and P. J. Sadler, Top. Organomet. Chem., 2010, 32, 21. See also its references and citations.

10 M. Guo, H. Sun, H. J. McArdle, L. Gambling and P. J. Sadler. Biochemistry 2000, 39, 10023.

11 C. V. Christodoulou, A. G. Eliopoulos, L. S. Young, L. Hodgkins, D. R. Ferry and D. J. Kerr, Br. J. Cancer, 1998, 77, 2088.

12 M. L. McLaughlin, J. M. Cronan, T. R. Schaller and R. D. Snelling. J. Am. Chem. Soc., 1990, 112, 8949. 
13 For a detailed review of this area see: T. Cai-Ping, L. Yi-Ying, J. Liang-Nian and M. Zong-Wan, Metallomics, 2014, 6, 978.

14 For a more detailed description of autophogy see: D. Glick, S. Barth, and K. F. Macleod, J. Pathol., 2010, 221, 3.

15 L. Koubkova, R. Vyzula, J. Karban, J. Pinkas, E. Ondrouskova, B. Vojtesek and R. Hrstka, Invest. New Drugs, 2015, 33, 1123.

16 V. R. Lopes, V. Loitto, J.-N. Audinot, N. Bayat, A. C. Gutleb and S. Cristoba, J. Nanobiotechnol., 2016, 14, 22.

17 For detailed discussion of cell death modes see: L. Galluzzi, I. Vitale, J. M. Abrams, E. S. Alnemri, E. H. Baehrecke, M. V. Blagosklonny, T. M. Dawson, V. L. Dawson, W. S. El-Deiry, S. Fulda, E. Gottlieb, D. R. Green, M. O. Hengartner, O. Kepp, R. A. Knight, S. Kumar, S. A. Lipton, X. Lu, F. Madeo, W. Malorni, P. Mehlen, G. Nuñez, M. E. Peter, M. Piacentini, D. C. Rubinsztein, Y. Shi, H.-U. Simon, P. Vandenabeele, E. White, J. Yuan, B. Zhivotovsky, G. Melino and G Kroemer, Cell Death and Differentiation, 2012, 19, 107.

18 E-J. Park, S. Y. Lee, G-H. Lee, D-W. Kim, Y. Kim, M-H. Cho and J. H. Kim, Toxicology Lett. 2014, 230, 69.

19 S. Elmore, Toxicologic Pathology, 2007, 35, 495.

20 S. Cuffe, C. M. Dowling, J. Claffey, C. Pampillón, M. Hogan, J. M. Fitzpatrick, M. P. Carty, M. Tacke and R. W. G. Watson, The Prostate, 2011, 71, 111.

21 J. H. Bannon, I. Fichtner, A. O'Neill, C. Pampillón, N. J. Sweeney, K. Strohfeldt, R. W. Watson, M. Tacke, and M. M. Mc Gee, Br. J. Cancer, 2007, 97, 1234.

22 K. O'Connor, C. Gill, M. Tacke, F.-J. K. Rehmann, K. Strohfeldt, N. Sweeney, J. M. Fitzpatrick and R. W. G. Watson, Apoptosis 2006, 11, 1205.

23 L. Kater, J. Claffey, M. Hogan, P. Jesse, B. Kater S. Strauß, M. Tacke and A. Prokop, Toxicology in Vitro, 2012, 26, 119.

24 I. Vermes, C. Haanen, H. Steffens-Nakken, C. Reutelingsperger. J. Immunol Methods 1995, 184, 39

25 A. D. Tinoco, H. R. Thomas, C. D. Incarvito, A. Saghatelian, and A. M. Valentine, Proc. Nat. Acad. Sci., 2012, 109, 5016.

26 T. B. Parks, Y. M. Cruz, and A. D. Tinoco, Inorg. Chem., 2014, 53, 1743.

27 J. T. Rashkow, S. C. Patel, R. Tappero and Balaji Sitharaman, J. R. Soc. Interface, 2014, 11, 20131152.

28 M. Cini, H. Williams, M. W. Fay, M. S. Searle, S. Woodward and T. D. Bradshaw, Metallomics, 2016, 8, 286 and references therein.

29 M. Miller and E. Y. Tshuva, Eur. J. Inorg. Chem. 2014, 1485 and references therein.

30 T. A. Immel, M. Debiak, U. Groth, A. Burkle and T. Huhn, ChemMedChem, 2009, 4, 738.

31 C. M. Manna, O. Braitbard, E. Weiss, J. Hochman and E. Y. Tshuva, ChemMedChem 2012, 7, 703.

32 S. Meker, O. Braitbard, M. D. Hall, J. Hochman, and E. Y. Tshuva, Chem. Eur. J., 2016, 22, 9986.

33 J. Schur, C. M. Manna, A. Deally, R. W. Köster, M. Tacke, E. Y. Tshuva and Ingo Ott, Chem. Commun 2013, 49, 4785.

34 L. Schermelleh, R. Heintzmann and H. Leonhardt, J. Cell Biol., 2010, 190, 165. 
35 R. S. Riley, Hematol. Oncol. Clin. N., 2002, 16, xi.

36 I. Nicoletti, G. Migliorati, M. C. Pagliacci, F. Grignani and C. Riccardi, J. Immunol. Methods, $1991,139,271$.

37 M. E. Qazzaz, V. J. Raja, K. H. Lim, T. S. Kam, J. B. Lee, P. Gershkovich and T. D. Bradshaw, Cancer Lett., 2016, 370, 185.

38 L. Yan and G. Marriott, Curr. Opin. Chem. Biol., 2003, 7, 635.

39 Y. L. Yan and G. Marriott, Method. Enzymol., 2003, 360, 561.

40 J. Klose, Humangenetik, 1975, 26, 231.

41 E. C. Schirmer, L. Florens, T. L. Guan, J. R. Yates and L. Gerace, Science, 2003, 301, 1380.

42 C. B. Moore, E. H. Guthrie, M. T. H. Huang and D. J. Taxman, Methods Mol. Biol., 2010, 629, 139.

43 D. Sims, A. M. Mendes-Pereira, J. Frankum, D. Burgess, M. A. Cerone, C. Lombardelli, C. Mitsopoulos, J. Hakas, N. Murugaesu, C. M. Isacke, K. Fenwick, I. Assiotis, I. Kozarewa, M. Zvelebil, A. Ashworth and C. J. Lord, Genome Biol., 2011, 12, R104.

44 J. M. J. Logan, K. J. Edwards, N. A. Saunders and J. Stanley, J. Clin. Microbiol., 2001, 39, 2227.

45 T. Mahmood and P. C. Yang, N. Am. J. Med. Sci., 2012, 4, 429.

46 D. D. Rao, J. S. Vorhies, N. Senzer and J. Nemunaitis, Adv. Drug Deliver. Rev., 2009, $61,746$.

47 B. S. Tan, K. H. Tiong, A. Muruhadas, N. Randhawa, H. L. Choo, T. D. Bradshaw, M. F. G. Stevens and C. O. Leong, Mol. Cancer Ther., 2011, 10, 1982.

48 S. Sur, R. Pagliarini, F. Bunz, C. Rago, L. A. Diaz, Jr., K. W. Kinzler, B. Vogelstein and N. Papadopoulos, Proc. Nat. Acad. Sci., 2009, 106, 3964.

49 P. Mali, L. Yang, K. M. Esvelt, J. Aach, M. Guell, J. E. DiCarlo, J. E. Norville and G. M. Church, Science, 2013, 339, 823.

50 A. M. Mendes-Pereira, D. Sims, T. Dexter, K. Fenwick, I. Assiotis, I. Kozarewa, C. Mitsopoulos, J. Hakas, M. Zvelebil, C. J. Lord and A. Ashworth, Proc. Nat. Acad. Sci., 2012, 109, 2730. 